\title{
Long term morphological evolution of the Gold Coast Seaway: Historical and Numerical analysis
}

\author{
Mahnaz Sedigh ${ }^{1}$, Rodger Tomlinson ${ }^{2}$, Aliasghar Golshani ${ }^{3}$, Nick Cartwright ${ }^{4}$
}

Introduction

The Gold Coast Seaway is located on the Australian east coast linking an intra-coastal waterway known as The Broadwater with the Pacific Ocean. The reasons for construction of the Gold Coast Seaway and the associated sand by-passing system in the 1980s were stabilising the entrance, maintaining a safe navigable channel, preventing shoreline erosion to the north and maintaining an adequate beach width to the south.

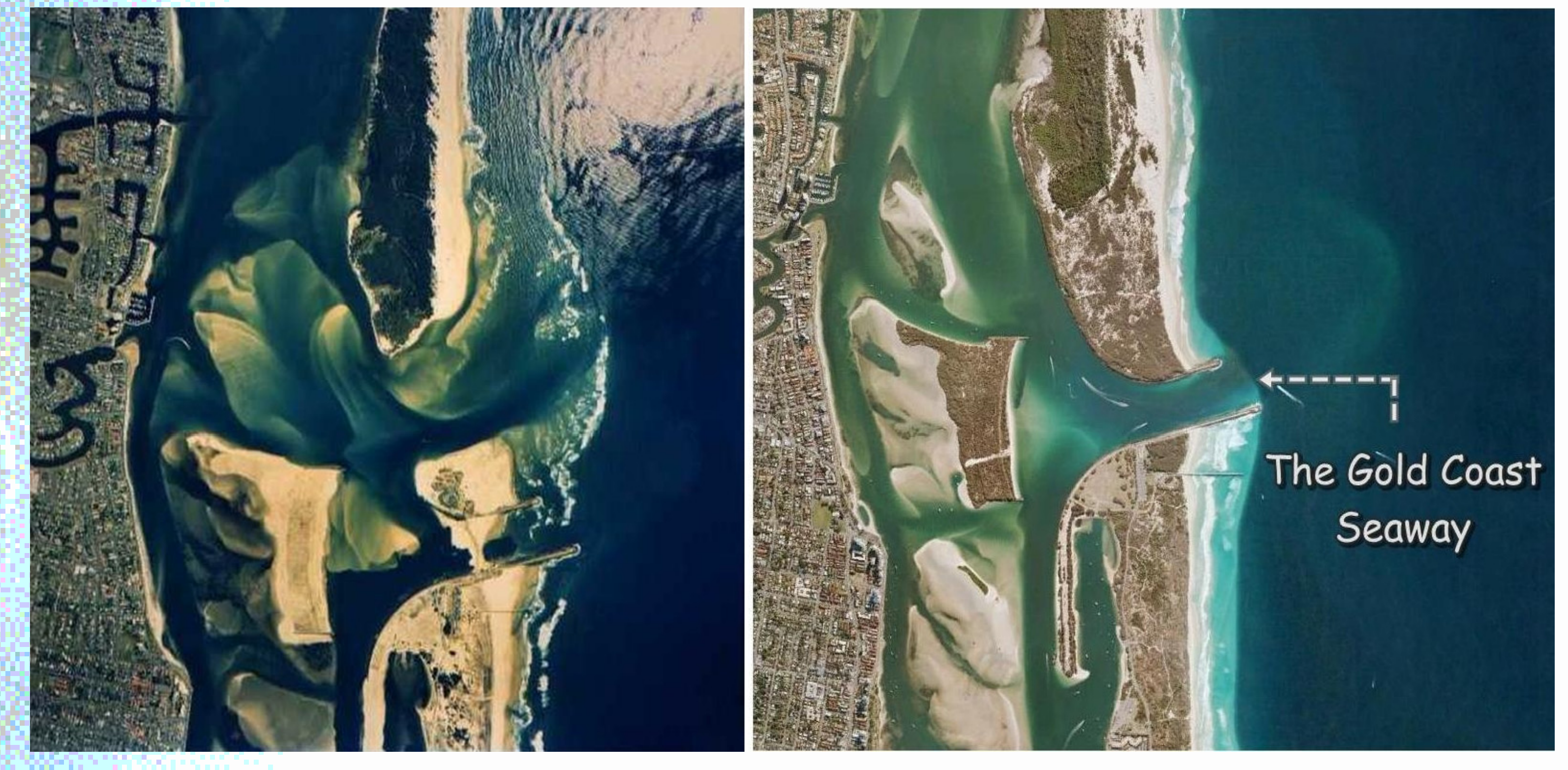

Nerang river Outlet during (Left) and after (Right) construction of The Gold Coast Seaway

\section{Purpose of the study and Methods}

First, historical bathymetric data has been collated to map out the trends of morphological changes and ebb-delta growth from 2004 to 2011.

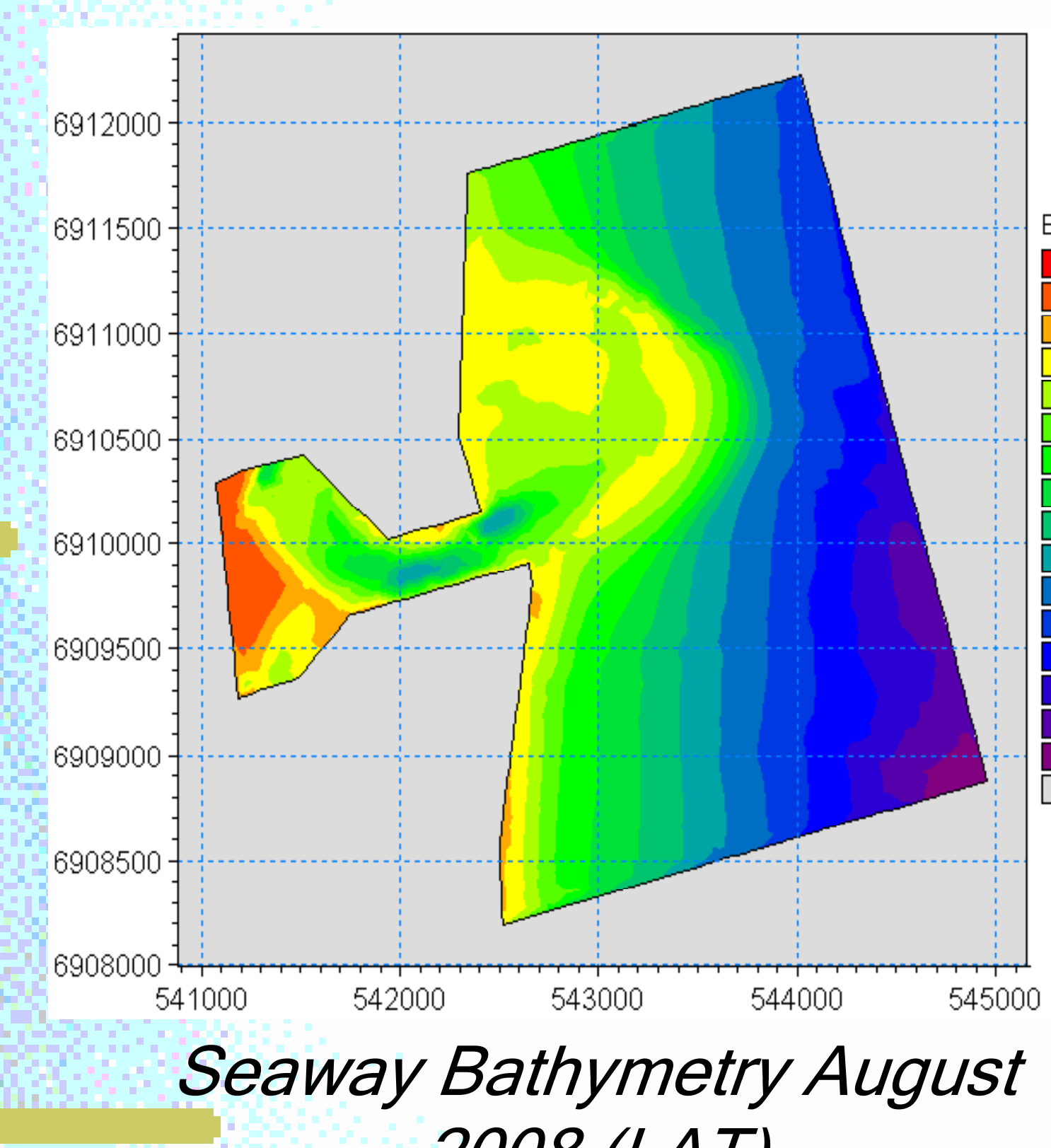
2008 (LAT)

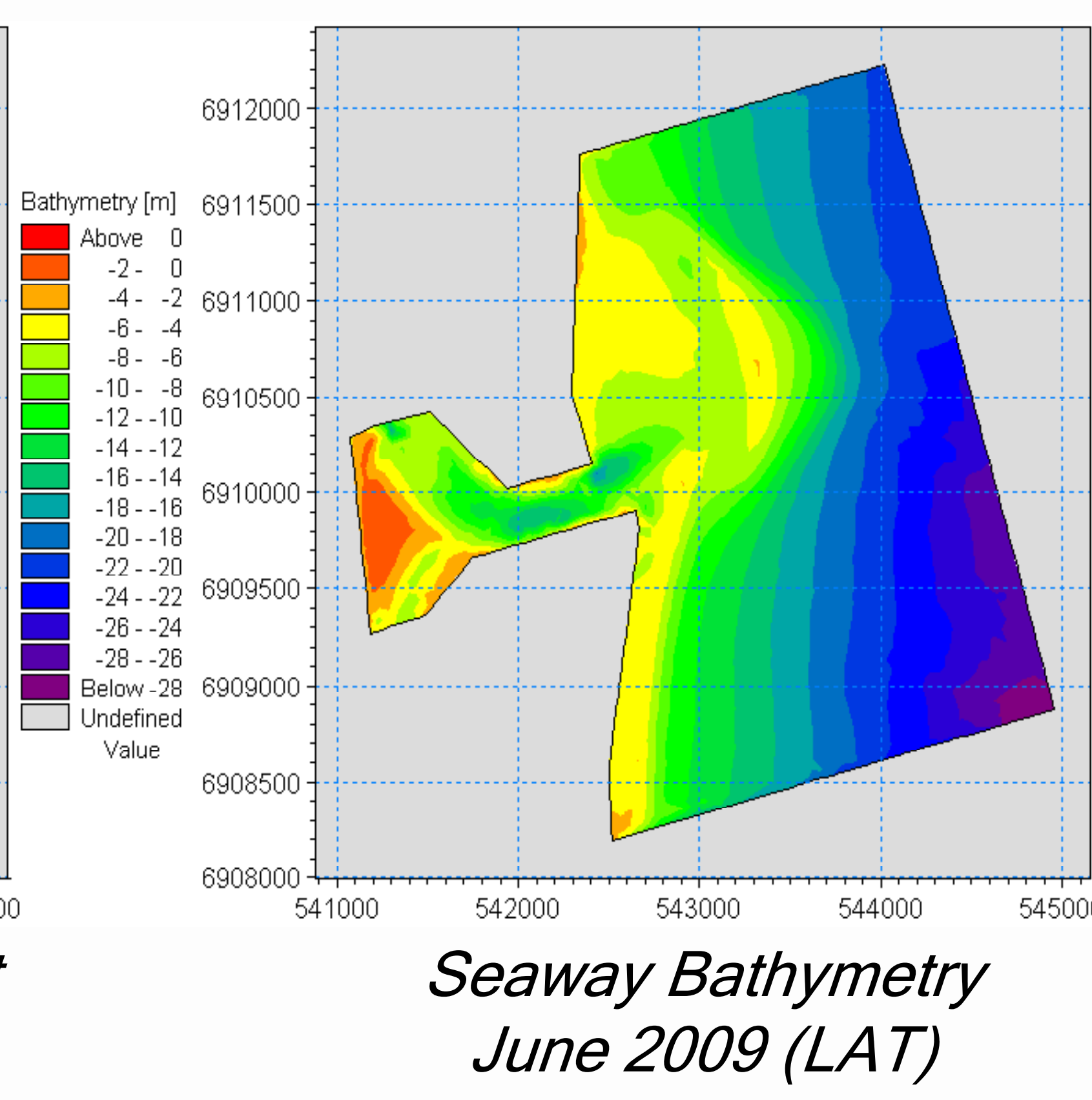

June 2009 (LAT)

Then, the trend of morphological changes and the environmental and anthropogenic drivers which have caused them analysed.

\section{- Offshore wave data}

The C-ERA-40 (1958 - 2001) (Caires and Sterl, 2005) and ERAInterim (1989 - present) data sets which were extracted by Splinter et al. (2010) research from grid point coordinates $(154.5,-28.5)$ located roughly $122 \mathrm{~km}$ south east from the Gold Coast Seaway is used.

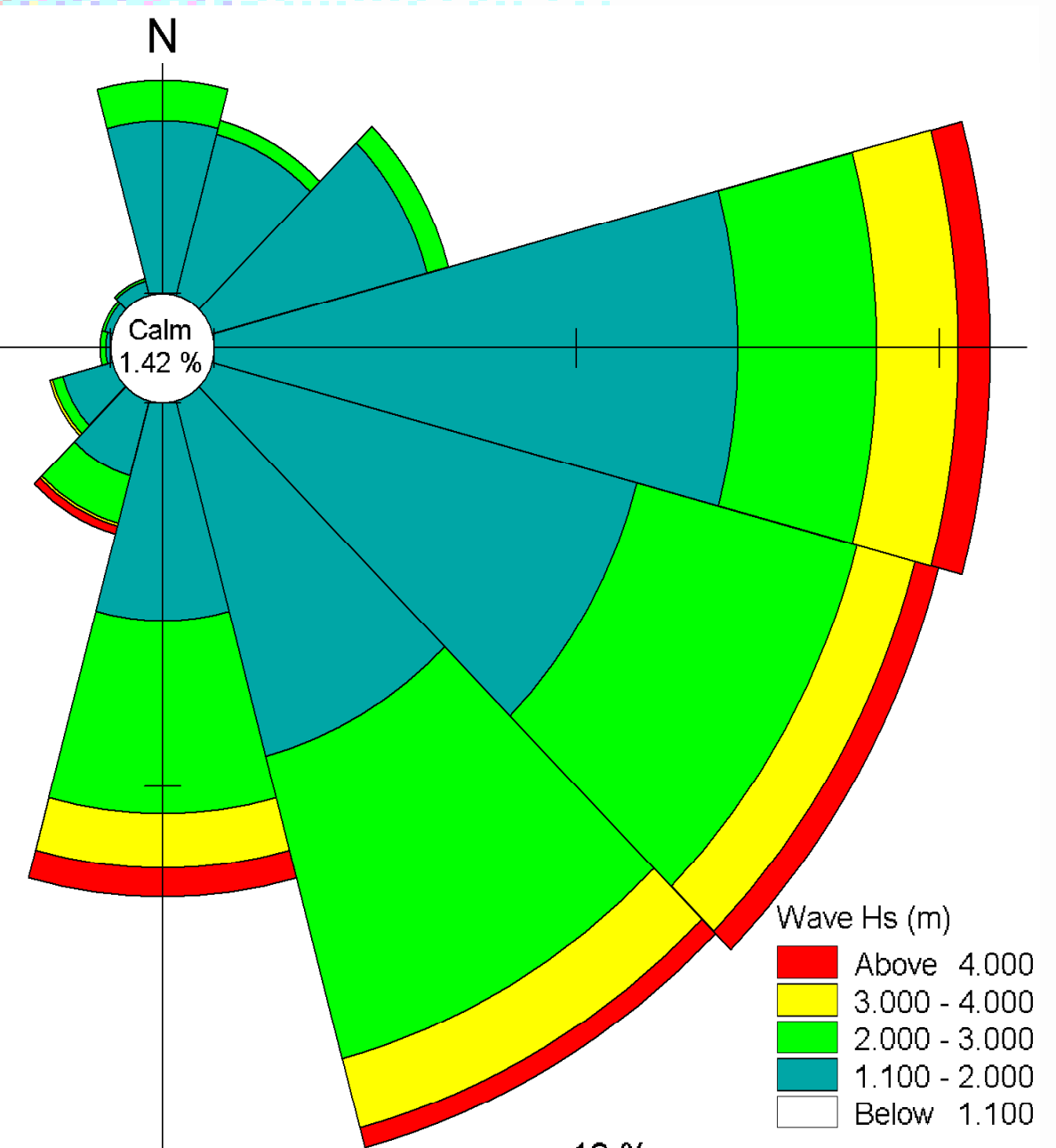

Offshore wave Hs Aug 2008 - Jun 2009

\section{- Bypassing data}

Volume of bypassing from 2004 to 2011 was plotted and shown that bypassing was done at a average rate of $56167 \mathrm{~m}^{3} /$ month during these years

\section{* Dredging Data}

The amount of dredging in the channels is not significant in terms of the morphological evolution of Ebb-tidal delta, so this was neglected in the analysis at this stage.

\section{Delta Crest Movement}

The seaward edge of the delta crest (at -6m LAT depth) is chosen as a reference line for analysing the movement of the delta.

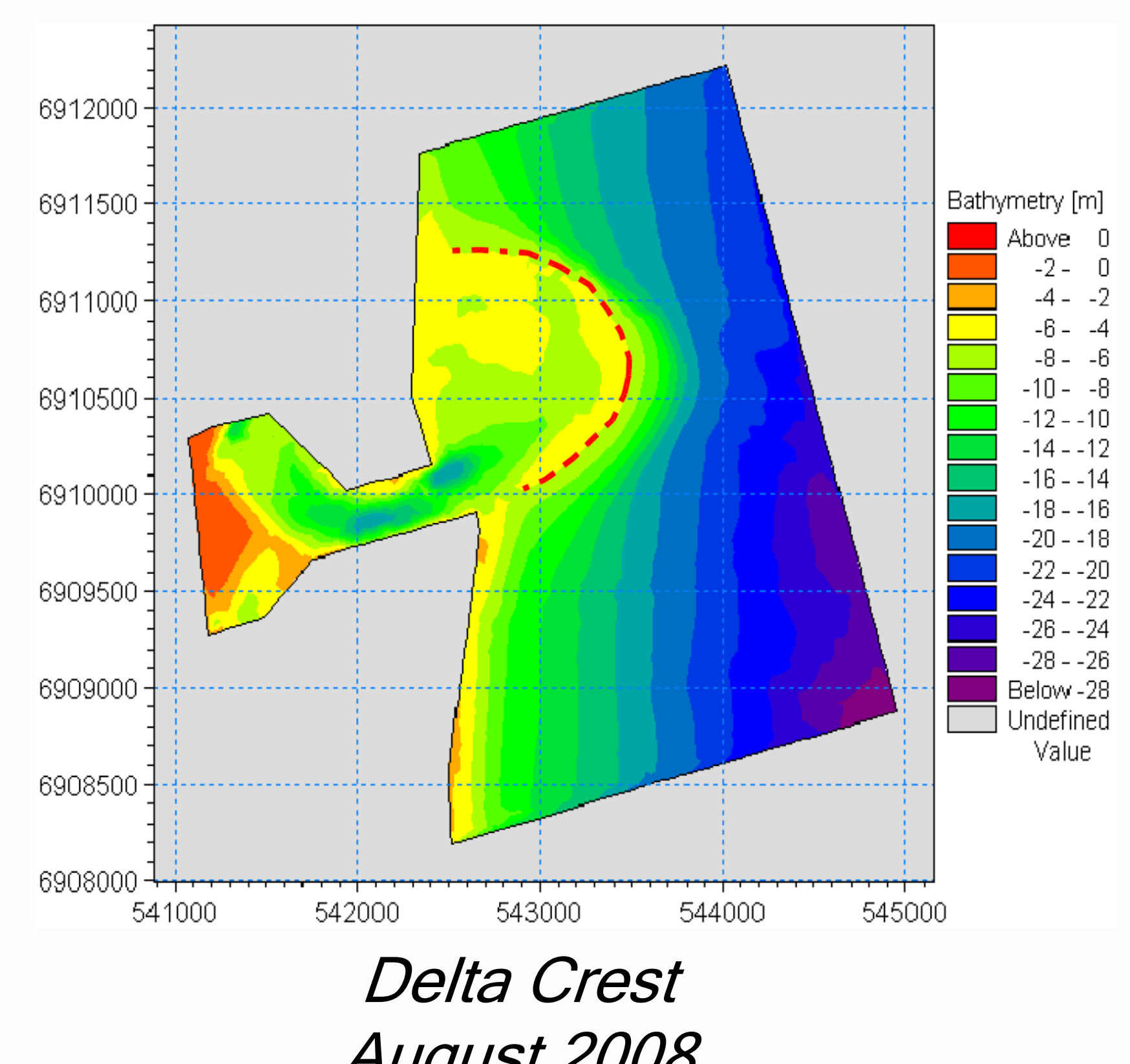

Results

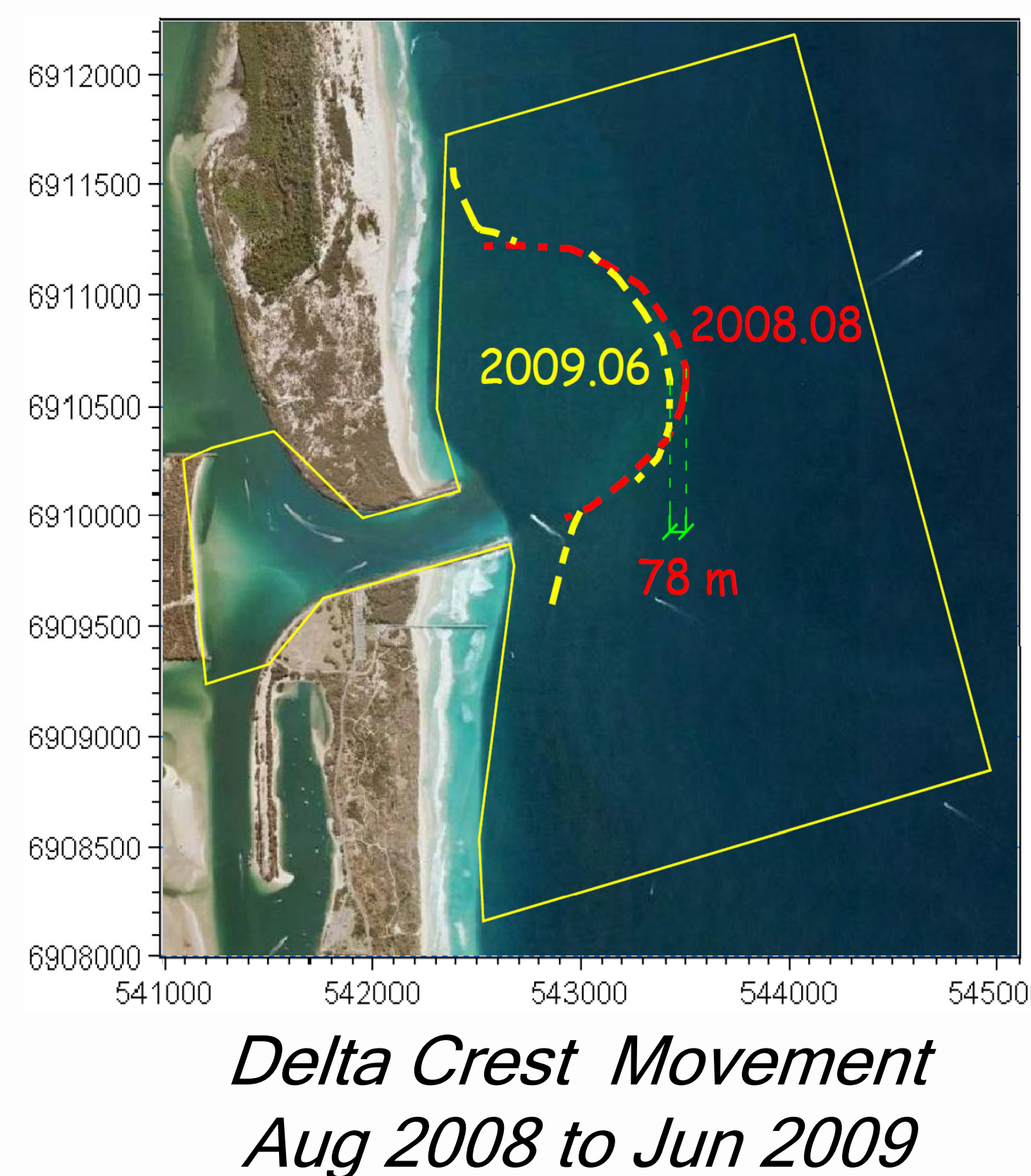

* Bathymetric changes

Morphological changes are expressed in terms of volumes of erosion or deposition in ebb delta shoal area, and in terms of changes in the distance offshore to the crest of the delta.

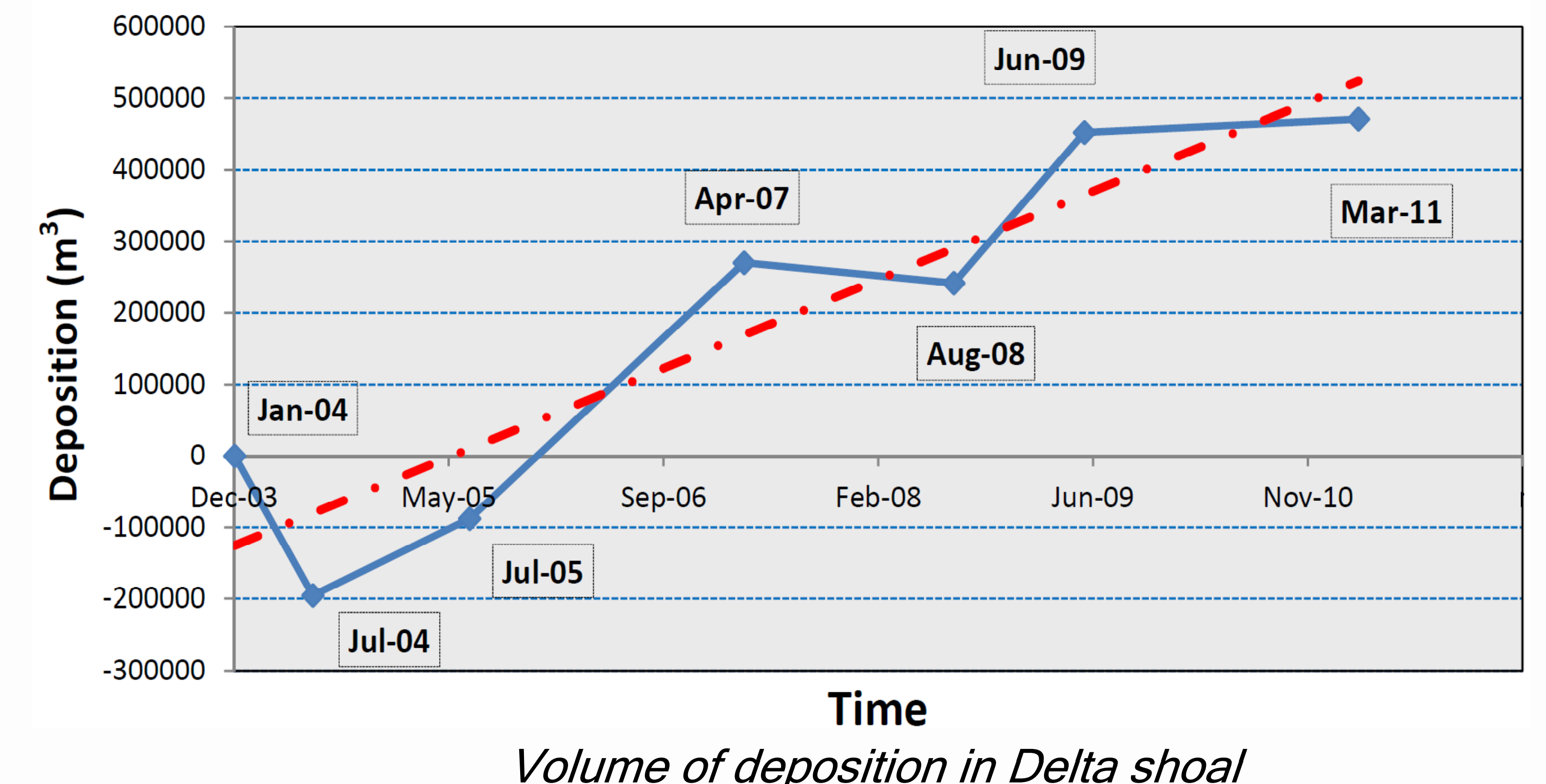

Despite the on-going bypassing, the delta shoal is still growing at an approximate rate of $7550 \mathrm{~m}^{3} /$ month.

\section{* Delta Crest Movement}

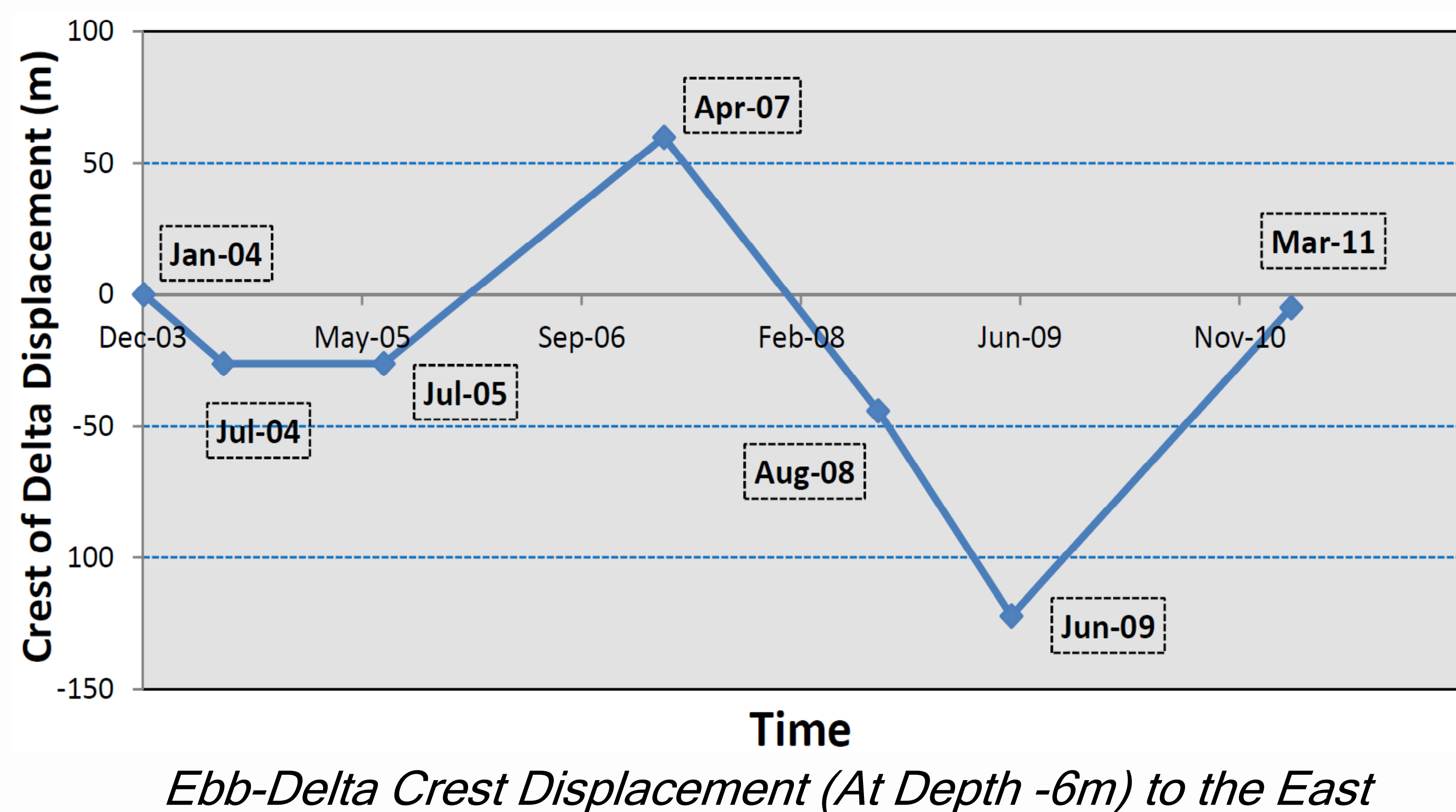
(shoreward is positive)

\section{Conclusion}

According to the analysis it seems that despite of existence of bypassing system the Seaway ebb-tidal delta is still growing. The major parameter that caused sudden changes in the morphology of the delta shoal seems to be large storm activities like the one in Tropical Cyclone Hamish early in 2009 and the East Coast Low (ECL) in May 2009. These events not only caused a rapid increase in the rate of deposition on the delta shoal, but also resulted in a shoreward migration of the delta crest. The delta seems to have gradual recovery after storms both in volume of sedimentation and configuration, but the rate of deposition is still overcoming the natural recovery and bypassing efforts.

A nested numerical model using MIKE 21 CAMS has been developed to compare the trend of morphological change using numerical modelling - which is at the calibration stage.

\section{References}

Caires, S. and Sterl, A., 2005. A New Nonparametric method to Correct Model Data: Application to Significant Wave Height from the ERA-40 ReAnalysis. Journal of Atmospheric and Oceanic Technology, 22: 443-459. Splinter, K.D., Golshani, A., Stuart, G. and Tomlinson, R., 2010. Spatial and temporal variability of longshore transport along Gold Coast, Australia, ICCE. 